\title{
Bước đầu xây dựng bộ chỉ thị SSR của DNA dưa leo và nhiệt độ bắt cặp tối ưu của các mồi SSR cho phản ứng PCR
}

\section{Initial SSR data set for cucumber breeding and optimal annealing temperatures of SSR primers in PCR reactions}

\author{
Lương Hiếu Ngân ${ }^{1}$, Hồ Thị Bích Phượng ${ }^{1}$, Nguyễn Như Thành ${ }^{2}$, Hoàng Thị Thuỳ², \\ Cao Tiến Sang ${ }^{2}$, Vũ Quốc Trưởng ${ }^{2}$, Lê Thị Trúc Linh ${ }^{3 *}$, Lê Thị Kính ${ }^{3}$ \\ ${ }^{1}$ Nghiên cứu tự do, Thành phố Hồ Chí Minh, Việt Nam \\ ${ }^{2}$ Công ty TNHH Hạt giống Tân Lộc Phát, Việt Nam \\ ${ }^{3}$ Trường Đại Học Mở Thành phố Hồ Chí Minh, Việt Nam \\ "Tác giả liên hệ, Email: linh.ltt@ou.edu.vn
}

THÔNG TIN

DOI: $10.46223 / \mathrm{HCMCOUJS}$. tech.vi.16.1.1872.2021

Ngày nhận: 06/05/2021

Ngày nhận lại: 20/05/2021

Duyệt đăng: 25/05/2021

Tì khóa:

chọn giống; chỉ dấu phân tử; dưa leo; SSR

Keywords:

cucumber; plant breeding; molecular marker; SSR

\section{TÓM TẮT}

Bản đồ liên kết phân tử với mật độ chỉ thị cao cần được xác định trước khi thực hiện chọn giống bằng DNA marker trong đó các chỉ thị này có sự liên kêt chặt với các tính trạng quan tâm. SSR (Simple Sequence Repeat - Trình tự lặp lại đơn giản) là một marker phân tử được dùng để xây dựng bản dồ liên kết phân tử và có thể phân biệt được các dạng dị hợp và đồng hợp của gene. Mục tiêu của nghiên cứu là xây dựng bộ chỉ thị SSR có liên kết với các tính trạng quan trọng trong chọn giống dưa leo và xác định được điều kiện tối ưu cho phản ứng PCR khuyếch đại DNA dưa leo từ những SSR này. Thực hiện khai thác in silico để xây dựng bộ dữ liệu SSR. Tối ưu hoá phản ứng PCR bằng chạy gradient nhiệt độ cho các mồi SSR. Chúng tôi đã xác định được $52 \mathrm{SSR}$ có liên kết với các tính trạng quan trọng trong chọn giống dưa leo. Điều kiện nhiệt độ bắt cặp tối ưu 46 SSR trong phản ứng PCR khuếch đại DNA dưa leo đã được xác định. Đây là dữ liệu quan trọng cho bước sàng lọc các cây phân ly trong quá trình chọn giống dưa leo tiếp sau đó.

\section{ABSTRACT}

Genetic maps with a high density of molecular markers are essential for plant breeding. SSR (Simple Sequence Repeat) is a molecular marker for creating genetic maps and distinguishing heterozygous and homozygous plants. The main aim of this study was to construct SSRs associated with key traits in cucumber breedings and to determine the optimum conditions for PCR reactions to amplify cucumber DNA utilizing these SSRs. An in silico survey was performed to mine the SSR data set. Optimization of PCR reaction by running temperature gradients for all the SSR primers. We identified 52 SSRs that are associated with important traits in cucumber breeding. Also, the optimal 
annealing temperatures for PCR of 46 SSRs were determined.

These are important data for the next screening steps for segregating plants for further cucumber breeding.

\section{Giới thiệu}

Chọn giống bằng DNA marker đòi hỏi trước hết phải có bản đồ liên kết phân tử với mật độ chỉ thị cao và bản đồ QTLs (Quantitative Trait locus). Các chỉ thị này có sự liên kết chặt với các tính trạng quan tâm. SSR là vùng lặp lại đơn giản các đoạn DNA từ $02 b p$ đến $08 \mathrm{bp}$ phân bố trong hệ gene của động vật và thực vật. Số lượng chuỗi lặp lại thay đổi theo từng cá thể của mỗi loài. Đồng thời đây là một marker có thể phân biệt được các dạng dị hợp và đồng hợp của gene. Vì vậy có thể dùng để đánh giá sự đa dạng di truyền hoặc sự biến dị trong từng cá thể.

Một số bản đồ liên kết gene được xây dựng bằng SSR marker (và một số loại DNA marker khác) đã được xây dựng dựa trên các quần thể phân ly được tạo ra từ các dòng dưa leo bố mẹ thuần chủng như sau: Fazio, Staub, và Stevens (2003) xây dựng một bộ bản đồ liên kết gồm 171 dòng tái tổ hợp cận giao được tạo ra từ lai giữa dòng G421 (determinate, toàn hoa cái $(\mathrm{F})$, lá có kích thước tiêu chuẩn) và dòng H-19 (indeterminate, monoecious, little-leaf (11) line. Bản đồ di truyền (131 điểm) được xây dựng dựa trên các cá thể cận giao tái tổ hợp này và 216 cá thể F2 chứa 14 SSRs, 24 SCARs, 27 AFLPs, 62 RAPDs, 01 SNP và 03 markers hình thái quan trọng về kinh tế [F (gynoecy), de (determinate habit), 11 (little leaf)]. Bảy nhóm liên kết trải rộng $706 \mathrm{cM}$ với khoảng cách trung bình giữa 02 marker là $5.6 \mathrm{cM}$ (Fazio et al., 2003). Ren và cộng sự (2009) đã sử dụng Sanger shotgun sequencing để phát triển dữ liệu SSR cho dưa leo (Ren et al., 2009). Thực hiện giải trình tự với độ phủ ba lần bộ gene và phân tích để tìm các vùng SSR tiềm năng. 1,940 SSR marker được tìm ra và sau đó được thực hiện PCR để xác định marker đa hình giữa dòng Gy14 và PI 183967. Từ đó 966 SSR marker được sử dụng để xây dựng bản đồ liên kết gene được chia thành 07 nhóm (Ren et al., 2009). Weng, Johnson, Staub, và Huang (2010) sử dụng 821 SSR xây dựng bản đồ liên kết cho quần thể cận giao tái tổ hợp xuất phát từ 02 dòng dưa leo, Gy7 (synonym G421) và H-19. 140 (17.0\%) SSR marker được xác định là đa hình giữa bố mẹ. Kết hợp với 42 marker SCAR và SSR đã xác định trước đó, các marker này được sử dụng để xây dựng bản đồ liên kết bằng sử dụng 46 RILs và 176 mapped loci bao phủ khoảng $400 \mathrm{cM}$ khắp bảy nhóm liên kết. Số lượng của các loci được xây dựng trên các nhóm liên kết từ 01 tới 07 tương ứng là $11,6,35,18,46,45$, và 15 (Weng et al., 2010). Bản đồ di truyền dựa trên quần thể cận giao từ hai dòng Gy7 $\times$ H-19 có 94 marker chung với bản đồ liên kết xây dựng từ quần thể tái tổ hợp cận giao xuất phát từ $\mathrm{C}$. sativus var. sativus lineGy14andC.sativusvar.hardwickiiAlef.R.PI183967 (Weng et al., 2010).

Đến năm 2011, bản đồ liên kết xây dựng dựa trên các dòng tái tổ hợp cận giao được tạo ra từ dòng toàn hoa cái $9119 \mathrm{Gt}$ và dòng hoa đực nhiều hơn hoa cái $9930 \mathrm{Gt}$ được xây dựng (Miao et al., 2011). Công trình nghiên cứu này sử dụng trình tự gene được xây dựng từ trình tự bộ gene của Huang và cộng sự (2009) và dữ liệu SSR của Ren và cộng sự (2009). Bản đồ di truyền của dưa leo gồm 07 nhóm liên kết tương ứng với 07 NST với 248 SSR markers và 07 loci tính trạng bao phủ vùng gene có kích thước $711.9 \mathrm{cM}$ (centimorgan) với khoảng cách trung bình là $2.8 \mathrm{cM}$.

Như vậy, bản đồ liên kết giữa bộ marker SSR và cụ thể là 07 nhóm liên kết ở dưa leo đã được xác định. Đây là cơ sở dữ liệu quan trọng về trình tự, vị trí, khoảng cách di truyền giữa các marker, và đặc biệt quan trọng là mối liên kết giữa marker với tính trạng quan tâm.

Với mục tiêu chuyển một số đặc tính ưu thế lai từ dòng bố sang dòng con lai trong kế hoạch nghiên cứu lâu dài hơi cho dưa leo, chúng tôi cần một bộ marker phân tử có liên kết với một số tính trạng quan trọng trong chọn giống dưa leo và trải đều trên bộ NST của dưa leo. Do 
vậy, trong nghiên cứu này chúng tôi thực hiện khảo sát cơ sở dữ liệu để xây dựng bộ SSR liên kêt với một số tính trạng nông học quan trọng và bước đầu xây dựng quy trình PCR để khuếch đại DNA dưa leo cho các SSR này.

\section{Cơ sở lý thuyết và mô hình nghiên cứu}

\subsection{Khảo sát in silico để xác định các SSR liên kết với các nhóm liên kết trên dua leo}

Tiến hành khai thác dữ liệu để xây dựng bộ chỉ thị phân tử liên kết với các gene/ QTLs với các tính trạng nông học quan trọng và khả năng kháng bệnh của các dòng dưa leo; và chỉ thị phân tử trải đều trên 07 nhóm liên kết của dưa leo. Trong đó dữ liệu là các kết quả nghiên cứu được công bố trên các tạp chí khoa học uy tín trên thế giới về: trình tự của bộ gene đưa leo; đặc điểm di truyền của các tính trạng quan trọng trong chọn giống dưa leo. Tiến hành xác định các QTLs/gene qui định cho tính trạng mong muốn và các chỉ thị phân tử đi kèm.

\subsection{Tách chiết DNA tù lá dưa leo}

Vật liệu ban đầu là 02 dòng dưa leo Cucumis sativus $L$. có kiểu gene quy định cho cây dưa leo toàn hoa cái và toàn hoa đực đã kiểm tra trước đó. Lúc cây được 05 lá thật thì tiến hành thu mẫu lá bằng cách cắt một phần của lá thật thứ tư bỏ vào ống nghiệm $180 \mathrm{ml}$. Vật liệu ban đầu được cung cấp bởi công ty hạt giống Tân Lộc Phát. DNA được tách chiết bằng DNAzol®Reagent (Thermal Fisher). Quy trình tách chiết như sau: Nghiền mô thực vật trong nitơ lỏng cùng với $0.3 \mathrm{ml}$ Plant DNAzol Reagent cho $0.1 \mathrm{~g}$ mẫu mô thực vật. Trộn dung dịch kỹ lưỡng bằng cách đảo nhẹ và ủ ở $25^{\circ} \mathrm{C}$ trong 05 phút. Cho $0.3 \mathrm{ml}$ chlorofrom, trộn đều và ủ ở $25^{\circ} \mathrm{C}$ trong 05 phút. Ly tâm 12,000 vòng/phút trong 10 phút và chuyển dịch nổi sang epppendorf mới. Cho vào epppendorf mới với $0.225 \mathrm{ml}$ Ethanol $100 \%$, trộn mẫu bằng cách đảo ngược $06-08$ lần và để bảo nhiệt độ phòng trong 05 phút. Ly tâm 5,000 vòng/phút trong 04 phút, bỏ dịch nổi. Cho vào eppendoft $0.3 \mathrm{~mL}$ DNAzol + Ethanol $100 \%$ wash (tỷ lệ 1:0.75), vortex, giữ mẫu trong 05 phút và ly tâm 5,000 vòng/phút trong 04 phút. Loại bỏ DNAzol + Ethanol $100 \%$ wash và thêm $0.3 \mathrm{~mL}$ Ethanol $75 \%$ trộn đều, ly tâm 5,000 vòng/phút trong 04 phút. Loại bỏ Ethanol, phơi khô

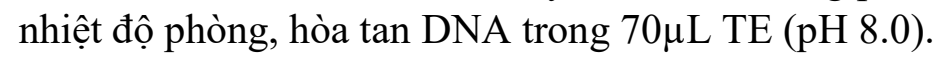

Nồng độ DNA sau khi tách chiết được xác định bằng máy Nanodrop (Thermal Fisher). Chất lượng DNA được đánh giá bằng tỉ số $\mathrm{A} 260 / 280$ và $\mathrm{A} 260 / 230$. Các mẫu DNA được bảo quản ở $-20^{\circ} \mathrm{C}$.

\subsection{PCR}

Phản ứng PCR thực hiện cho 50 mồi SSR được thực hiện với thành phần phản ứng thực hiện trong thể tích $20 \mu \mathrm{L}$ sử dụng phire tag polymerase (Thermal Fisher) theo hướng dẫn của nhà sản xuất với thành phần phản ứng như sau $35 \mathrm{ng} \mathrm{DNA}, 1 \mu \mathrm{L}$ mồi $\mathrm{F} 10 \mu \mathrm{M}, 1 \mu \mathrm{L}$ mồi $\mathrm{R} 10 \mu \mathrm{M}, 1$, $1 \mu \mathrm{L}$ dNTPs $10 \mathrm{mM}, 5 \mathrm{u}$ phire tag polymerase. Phản ứng được thực hiện với chu trình nhiệt bao gồm biến tính $98^{\circ} \mathrm{C} 30 \mathrm{~s}$, tiếp theo $35 \mathrm{chu}$ kỳ với biến tính ở $98^{\circ} \mathrm{C} 5 \mathrm{~s}$, nhiệt độ bắt cặp của mồi $5 \mathrm{~s}$ (Bảng 1), và kéo dài phản ứng ở $72^{\circ} \mathrm{C} 5 \mathrm{~s}$. Cuối cùng, hoàn thành phản ứng ở $72^{\circ} \mathrm{C} 30 \mathrm{~s}$.

Tiến hành lập bảng nhiệt độ bắt cặp cho 50 mồi đã đặt trước và thực hiện xác định 04 nhiệt độ gradient dựa trên nguyên tắc như sau: Nếu nhiệt độ nóng chảy giữa hai mồi $\mathrm{F}$ và $\mathrm{R}$ bằng nhau thì sẽ tăng và giảm nhiệt độ đi 02 độ; Nếu nhiệt độ. nóng chảy giữa hai mồi $\mathrm{F}$ và $\mathrm{R}$ cách nhau 1 độ thì lấy nhiệt độ lớn làm nhiệt độ trung tâm và sẽ tăng giảm nhiệt độ đi 02 độ; Nếu nhiệt độ nóng chảy giữa hai mồi $\mathrm{F}$ và $\mathrm{R}$ cách nhau 02 độ thì lấy nhiệt độ ở giữa làm nhiệt độ trung tâm và sẽ tăng giảm nhiệt độ đi 02 độ; Nếu nhiệt độ nóng chảy giữa hai mồi $F$ và $R$ cách nhau 03 độ thì lấy nhiệt độ độ lớn làm nhiệt độ trung tâm và tăng 03 độ; Nếu nhiệt độ nóng chảy giữa hai mồi $\mathrm{F}$ và $\mathrm{R}$ cách nhau 06-07 độ thì lấy nhiệt độ trung bình làm trung tâm và nhiệt độ 
nhỏ của 02 mồi sẽ giữ nguyên. Bảng nhiệt độ bắt cặp cho các mồi được tóm tắt trong Bảng 1 . Những mồi có dãy gradient nhiệt độ gần nhau được nhóm lại để cùng chạy cùng gradient nhiệt độ.

\section{Bảng 1}

Gradient nhiệt độ cho từng SSR

\begin{tabular}{|c|c|c|}
\hline Mồi & Nhiệt độ & Nhiệt độ thực tế chọn \\
\hline $3,4,6,26$ & $54-56-58$ & $54.1-55.6-58.1$ \\
\hline $2,18,20,24,27,29$ & $55-57-59$ & $55-57.2-59$ \\
\hline 19 & $56-58-60$ & $56.1-57.6-60.1$ \\
\hline $5,7,17,21,22,23,25$ & $56-57-59-61-62$ & $56-57.1-58.6-60.9-62$ \\
\hline $9,10,12,13,14,15,16$ & $58-59-61-63-64$ & $58-59.1-61.4-62.9-64$ \\
\hline $1,8,11$ & $60-62-64$ & $60-62.2-64$ \\
\hline 28 & $60-63-66$ & $60-62.6-66$ \\
\hline 34 & $52-54-56$ & $52 ; 54.2 ; 56$ \\
\hline $30,36,47$ & $51-53-55-57-58$ & $51 ; 53.2 ; 54.9 ; 57.4 ; 58$ \\
\hline $32,40,44,48,49$ & $54-56-58$ & $54 ; 56.2 ; 58$ \\
\hline $35,37,38,42,43,50,52$ & $55-57-59$ & $55.1 ; 56.6 ; 59.1$ \\
\hline 31,46 & $54-56-58-60-61$ & $54 ; 56.2 ; 57.9 ; 59.7 ; 61$ \\
\hline 51 & $58-60-62$ & $57.1 ; 59.4 ; 60.9$ \\
\hline 33 & $59-61-63$ & $58.9 ; 61.4 ; 63$ \\
\hline
\end{tabular}

Nguồn: Kết quả xử lý dữ liệu của nhóm tác giả

\section{4. Điện di polyacrylamide}

Thực hiện đổ gel polyacrylamide $20 \%$ bằng dung dịch $\mathrm{TBE} 1 \mathrm{X}$ với $1 \mathrm{M} \mathrm{DTT}$ và Amonium persulphate $10 \%$. Sau khi gel đông hoàn toàn, chuyển gel vào bồn diện di vào cho dung dịch $\mathrm{TBE}$ vào ngập giếng. Cho hỗn hợp gồm $10 \mu \mathrm{L}$ sản phẩm $\mathrm{PCR}$ và $2 \mu \mathrm{L}$ loading dye vào mỗi giếng. Tiến hành điện di với hiệu điện thế $90 \mathrm{~V}$. Ngay sau khi điện di, bảnggel được soi dưới đèn UV để ghi nhận kết quả.

\section{Kết quả nghiên cứu}

\subsection{Kết quả nghiên cúu}

3.1.1. Khai thác dũ liệu để xác định 50 SSR liên kết với nhũng tính trạng quan trong và liên kết chặt với các nhóm liên kết của dưa leo

Dữ liệu được khai thác là những công trình nghiên cứu đã được công bố trên các tạp chí uy tín có thực hiện khảo sát mối liên kết giữa các SSR và các giống dưa leo khác nhau trên thế giới. Chúng tôi tiến hành xác định trình tự của các primer, số lần trình tự lặp lại của nucleotide (motif), khả năng liên kết của các SSR này với một số đặc điểm quan trọng trong chọn giống của dưa leo như khả năng kháng bệnh, hình dạng quả, số lượng quả, hình dạng lá, thân. Bên cạnh đó, những SSR đã được chứng minh có khả năng được sử dụng để xác định đa dạng di truyền của 
các giống dưa leo cũng được thu nhận. Kết quả khai thác dữ liệu được tóm tắt trong Bảng 2.

\section{Bảng 2}

Bảng tổng hợp 52 SSR khai thác từ những công trình công bố về các SSR có liên kết với dưa leo

\begin{tabular}{|c|c|c|c|c|c|c|c|c|c|c|}
\hline SSR & Bệnh & Kháng & TLTK & Chr. & $\mathbf{c M}$ & Loci & Motif & $\begin{array}{c}\text { Fragment } \\
\text { size }\end{array}$ & $\begin{array}{c}\text { Forward } \\
\text { primer }\end{array}$ & $\begin{array}{c}\text { Reverse } \\
\text { primer }\end{array}$ \\
\hline 1 & \multirow{6}{*}{$\begin{array}{l}\text { Sương } \\
\text { mai } \\
\text { (mốc } \\
\text { sương) }\end{array}$} & \multirow{6}{*}{$\begin{array}{c}\text { nấm } \\
\text { Pseudoperon } \\
\text { ospora } \\
\text { cubensis }\end{array}$} & \multirow{6}{*}{$\begin{array}{l}\text { S. Zhang và } \\
\text { cộng sự (2013) }\end{array}$} & 1 & 19.0 & SSR31116 & (TA) 35 & 220 & $\begin{array}{c}\text { GAAGGCC } \\
\text { ATCAAGG } \\
\text { TATTACA } \\
\text { TCT }\end{array}$ & $\begin{array}{c}\text { CAAAC } \\
\text { CTTCT } \\
\text { ACATG } \\
\text { ATCTT } \\
\text { AATCT } \\
\text { TT } \\
\end{array}$ \\
\hline 2 & & & & 1 & 6.1 & SSR20705 & (TC) 20 & 140 & $\begin{array}{c}\text { CCTTTCCT } \\
\text { TACCCAT } \\
\text { CCCAT }\end{array}$ & $\begin{array}{l}\text { ACCCA } \\
\text { TTTGA } \\
\text { ATCAG } \\
\text { CTTCG } \\
\end{array}$ \\
\hline 3 & & & & 5 & 21.7 & SSR00772 & (AG) 12 & 172 & $\begin{array}{c}\text { AGAAGCG } \\
\text { TTGGGGG } \\
\text { AAAATA }\end{array}$ & $\begin{array}{l}\text { TGCTA } \\
\text { CCTCA } \\
\text { CATGG } \\
\text { TTTTG } \\
\end{array}$ \\
\hline 4 & & & & 5 & 10.9 & SSR11012 & (AT) 25 & 215 & $\begin{array}{c}\text { TCGTAAT } \\
\text { TTATGAA } \\
\text { AATAGAA } \\
\text { CGGT } \\
\end{array}$ & $\begin{array}{l}\text { CGATT } \\
\text { GCGCA } \\
\text { AAATG } \\
\text { TGTAT } \\
\end{array}$ \\
\hline 5 & & & & 6 & 98.8 & SSR16882 & (AT) 24 & 218 & $\begin{array}{l}\text { CACCTCA } \\
\text { ACTCCTC } \\
\text { CATTCAA }\end{array}$ & $\begin{array}{c}\text { TGGAG } \\
\text { GTCAT } \\
\text { TGAGA } \\
\text { CTTGC } \\
\quad \mathrm{T} \\
\end{array}$ \\
\hline 6 & & & & 5 & 7.9 & SSR16110 & (TA) 22 & 181 & $\begin{array}{c}\text { GGAATAT } \\
\text { GGAAGGA } \\
\text { AAGCCA }\end{array}$ & $\begin{array}{l}\text { ATCCC } \\
\text { CAATT } \\
\text { CCTCC } \\
\text { AAAAC } \\
\end{array}$ \\
\hline 7 & $\begin{array}{c}\text { Sương } \\
\text { mai } \\
\text { (mốc } \\
\text { sương) }\end{array}$ & $\begin{array}{c}\text { nấm } \\
\text { Pseudoperon } \\
\text { ospora } \\
\text { cubensis }\end{array}$ & $\begin{array}{l}\text { Nie và cộng sự } \\
\text { (2015) }\end{array}$ & 5 & 39.0 & SSR06303 & $(\mathrm{TCT}) 10$ & 136 & $\begin{array}{c}\text { AGCTCTC } \\
\text { AACAACG } \\
\text { AAGGGA }\end{array}$ & $\begin{array}{c}\text { TGACT } \\
\text { TTCTT } \\
\text { GATGG } \\
\text { TACCG } \\
\mathrm{C} \\
\end{array}$ \\
\hline 8 & \multirow{6}{*}{$\begin{array}{l}\text { Sương } \\
\text { mai } \\
\text { (mốc } \\
\text { sương) }\end{array}$} & \multirow{6}{*}{$\begin{array}{c}\text { nấm } \\
\text { Pseudoperon } \\
\text { ospora } \\
\text { cubensis }\end{array}$} & \multirow{6}{*}{$\begin{array}{l}\text { Naegele, } \\
\text { Quesada- } \\
\text { Ocampo, } \\
\text { Kurjan, } \\
\text { Saude, } \\
\text { và Hausbeck } \\
\text { (2016) }\end{array}$} & & & & (TGC)4 & 201 & $\begin{array}{c}\text { GTGGCTG } \\
\text { GAGGAAG } \\
\text { CAGTAG }\end{array}$ & $\begin{array}{l}\text { CATGT } \\
\text { TTCCC } \\
\text { AATCC } \\
\text { CCCGA } \\
\end{array}$ \\
\hline 9 & & & & & & & $(\mathrm{AGCA}) 3$ & 256 & $\begin{array}{c}\text { AACTAGG } \\
\text { CTTGGTC } \\
\text { TCGCAC }\end{array}$ & $\begin{array}{l}\text { GCACG } \\
\text { AGCAC } \\
\text { CAAAT } \\
\text { CGATC }\end{array}$ \\
\hline 10 & & & & & & & $\begin{array}{c}(\mathrm{CGA}) 4(\mathrm{~T} \\
\mathrm{GA}) 4\end{array}$ & 263 & $\begin{array}{c}\text { CGGAATT } \\
\text { CGCAGCT } \\
\text { CTTTCG }\end{array}$ & $\begin{array}{l}\text { CTTGC } \\
\text { GCGGC } \\
\text { TTGAT } \\
\text { TTTCT } \\
\end{array}$ \\
\hline 11 & & & & & & & (AAAG)3 & 282 & $\begin{array}{c}\text { GACCAAA } \\
\text { GTTCGCG } \\
\text { AATCGG }\end{array}$ & $\begin{array}{l}\text { GAAGT } \\
\text { CGGGC } \\
\text { TACTA } \\
\text { CGACG } \\
\end{array}$ \\
\hline 12 & & & & & & & (CTC)4 & 227 & $\begin{array}{c}\text { TTTAGGG } \\
\text { GAACACG } \\
\text { TGCCTC }\end{array}$ & $\begin{array}{l}\text { TACCT } \\
\text { TCAAC } \\
\text { AGTGC } \\
\text { GTGCA } \\
\end{array}$ \\
\hline 13 & & & & & & & (TCG)4 & 246 & $\begin{array}{l}\text { GCGATCC } \\
\text { AGTGCAT }\end{array}$ & $\begin{array}{l}\text { CTCTG } \\
\text { CCCAC }\end{array}$ \\
\hline
\end{tabular}




\begin{tabular}{|c|c|c|c|c|c|c|c|c|c|c|}
\hline SSR & Bệnh & Kháng & TLTK & Chr. & cM & Loci & Motif & $\begin{array}{c}\text { Fragment } \\
\text { size }\end{array}$ & $\begin{array}{l}\text { Forward } \\
\text { primer }\end{array}$ & $\begin{array}{l}\text { Reverse } \\
\text { primer }\end{array}$ \\
\hline & & & & & & & & & CGACTA & $\begin{array}{c}\text { GTGTA } \\
\text { CGG }\end{array}$ \\
\hline 14 & & & & & & & (CAA) 4 & 294 & $\begin{array}{c}\text { TGTTCAT } \\
\text { CTCGTGG } \\
\text { CAGTCC }\end{array}$ & $\begin{array}{l}\text { GTCTT } \\
\text { CAGCG } \\
\text { TCCAC } \\
\text { AGTCA } \\
\end{array}$ \\
\hline 15 & & & & & & & (TCG)4 & 246 & $\begin{array}{c}\text { GCGGTTC } \\
\text { TTGCAAC } \\
\text { GATCTC }\end{array}$ & $\begin{array}{l}\text { AACGC } \\
\text { GTTCT } \\
\text { CAGAT } \\
\text { GACGT }\end{array}$ \\
\hline 16 & & & & & & & (GGCC)3 & 263 & $\begin{array}{c}\text { TCTACGT } \\
\text { GGCCAAC } \\
\text { TGGTTC }\end{array}$ & $\begin{array}{l}\text { GAAAT } \\
\text { GCACG } \\
\text { ATCGA } \\
\text { CAGGC } \\
\end{array}$ \\
\hline 17 & \multirow[b]{2}{*}{$\begin{array}{l}\text { Sương } \\
\text { mai } \\
\text { (mốc } \\
\text { sương) }\end{array}$} & \multirow[b]{2}{*}{$\begin{array}{c}\text { nấm } \\
\text { Pseudoperon } \\
\text { ospora } \\
\text { cubensis }\end{array}$} & \multirow{2}{*}{$\begin{array}{l}\text { Call, Criswell, } \\
\text { Wehner, } \\
\text { Klosinska, } \\
\text { và Kozik } \\
\text { (2012); } \\
\text { Szczechura, } \\
\text { Staniaszek, } \\
\text { Klosinska, } \\
\text { và Kozik } \\
\text { (2015) }\end{array}$} & 1 & 12.7 & SSR05793 & (TA) 22 & 195 & $\begin{array}{c}\text { CCCTCTG } \\
\text { CTGCACA } \\
\text { TTATCC }\end{array}$ & $\begin{array}{c}\text { TGCAC } \\
\text { CAAGC } \\
\text { AATAA } \\
\text { CTTGT } \\
\text { C }\end{array}$ \\
\hline 18 & & & & 6 & $\begin{array}{c}101 . \\
5\end{array}$ & SSR01643 & (TA) 15 & 220 & $\begin{array}{l}\text { TGCAGGT } \\
\text { CGACAAT } \\
\text { TCAATAA }\end{array}$ & $\begin{array}{c}\text { TCAAA } \\
\text { AGGCA } \\
\text { CATGT } \\
\text { GATGT } \\
\text { C }\end{array}$ \\
\hline 19 & \multirow{3}{*}{$\begin{array}{l}\text { virus } \\
\text { CMV }\end{array}$} & \multirow{3}{*}{$\begin{array}{c}\text { CMV } \\
\text { (cucumber } \\
\text { mosaic } \\
\text { virus) }\end{array}$} & \multirow{3}{*}{$\begin{array}{l}\text { Shi và cô̂ng sự } \\
\text { (2018) }\end{array}$} & 6 & 27.6 & SSR9-56 & & 7637340 & $\begin{array}{c}\text { CAAAACA } \\
\text { AGGTAAG } \\
\text { GTGTATT } \\
\text { GGA }\end{array}$ & $\begin{array}{l}\text { TAAAA } \\
\text { GGCAG } \\
\text { GACAT } \\
\text { GCTCA }\end{array}$ \\
\hline 20 & & & & 6 & 35.4 & $\begin{array}{l}\text { SSR11- } \\
177\end{array}$ & & 9628895 & $\begin{array}{c}\text { CGTGGCA } \\
\text { TAAAACC } \\
\text { ACGAAT }\end{array}$ & $\begin{array}{c}\text { CAAAT } \\
\text { TCAAC } \\
\text { AAAAC } \\
\text { CCTAC } \\
\text { CA } \\
\end{array}$ \\
\hline 21 & & & & 6 & 32.6 & SSR11-1 & & 9025951 & $\begin{array}{l}\text { ACAAAGC } \\
\text { TTCTCCG } \\
\text { CAAATG }\end{array}$ & $\begin{array}{l}\text { GGAGG } \\
\text { GAAAG } \\
\text { GAAGG } \\
\text { AGAGA } \\
\end{array}$ \\
\hline 22 & \multirow{5}{*}{ Lá } & & \multirow{5}{*}{$\begin{array}{l}\text { Weng và công } \\
\text { sự (2010) }\end{array}$} & 5 & 17.7 & SSR03529 & (AT) 14 & 136 & $\begin{array}{c}\text { TGAATTG } \\
\text { AATAGAC } \\
\text { ACAACAA } \\
\text { TATGC } \\
\end{array}$ & $\begin{array}{l}\text { ACATG } \\
\text { TTGGG } \\
\text { ACTCC } \\
\text { ATGTG } \\
\end{array}$ \\
\hline 23 & & & & 5 & 18.5 & SSR07100 & (CT) 16 & 192 & $\begin{array}{l}\text { CACACCA } \\
\text { TTTACGG } \\
\text { TTATGGG }\end{array}$ & $\begin{array}{l}\text { CATTT } \\
\text { GGTTC } \\
\text { AGAAA } \\
\text { GGGGA } \\
\end{array}$ \\
\hline 24 & & & & 5 & 13.1 & SSR17464 & $\begin{array}{c}\text { (AGGAA) } \\
6\end{array}$ & 143 & $\begin{array}{c}\text { ATCTCAG } \\
\text { CCCTTGG } \\
\text { ATCCTT }\end{array}$ & $\begin{array}{c}\text { TCTTC } \\
\text { GAGAA } \\
\text { ATGGG } \\
\text { ATTTT } \\
\text { G }\end{array}$ \\
\hline 25 & & & & 5 & 26.5 & SSR01498 & (AT) 13 & 220 & $\begin{array}{c}\text { GGCGCCA } \\
\text { CAAATAT } \\
\text { TCAACA }\end{array}$ & $\begin{array}{c}\text { CCACA } \\
\text { AACGT } \\
\text { AAAGA } \\
\text { GATTC } \\
\text { ACA }\end{array}$ \\
\hline 26 & & & & 6 & 31.3 & SSR00170 & (AG)14 & 187 & $\begin{array}{c}\text { TTGCAAT } \\
\text { TTGTGCA } \\
\text { GGGATA }\end{array}$ & $\begin{array}{l}\text { AGGTA } \\
\text { TTATG } \\
\text { GCCCA }\end{array}$ \\
\hline
\end{tabular}




\begin{tabular}{|c|c|c|c|c|c|c|c|c|c|c|}
\hline SSR & Bệnh & Kháng & TLTK & Chr. & $\mathbf{c M}$ & Loci & Motif & $\begin{array}{c}\text { Fragment } \\
\text { size }\end{array}$ & $\begin{array}{c}\text { Forward } \\
\text { primer }\end{array}$ & $\begin{array}{l}\text { Reverse } \\
\text { primer }\end{array}$ \\
\hline & & & & & & & & & & AAGGG \\
\hline 27 & & & & 6 & 24.9 & SSR03940 & (AGG)11 & 213 & $\begin{array}{c}\text { GATTCTC } \\
\text { CGGAAAC } \\
\text { GGATTT }\end{array}$ & $\begin{array}{l}\text { GTCGT } \\
\text { TTTCC } \\
\text { GCGAT } \\
\text { TCTAC } \\
\end{array}$ \\
\hline 28 & Hoa & & Jat và cộng sự & 6 & 80.2 & SSR 18956 & (TAT)20 & 183 & $\begin{array}{c}\text { CGTATGT } \\
\text { ACGACAA } \\
\text { AATGTGA } \\
\text { ACAG }\end{array}$ & $\begin{array}{c}\text { TCGAA } \\
\text { ACCTC } \\
\text { AATAC } \\
\text { TTCTA } \\
\text { CCAA }\end{array}$ \\
\hline 29 & & & & 5 & 84.5 & SSR13251 & (AAG)14 & 162 & $\begin{array}{c}\text { GGTCAAT } \\
\text { CCAAAAG } \\
\text { AGAAAGC } \\
\text { A } \\
\end{array}$ & $\begin{array}{l}\text { ATCAA } \\
\text { CACCA } \\
\text { TTGAC } \\
\text { GACCA } \\
\end{array}$ \\
\hline 30 & & & & 5 & 10.9 & SSR16203 & (AT) 19 & 146 & $\begin{array}{c}\text { TCGAGGT } \\
\text { AAATCAA } \\
\text { AACCGA }\end{array}$ & $\begin{array}{l}\text { ATGTG } \\
\text { TCAAA } \\
\text { CCCAC } \\
\text { CCATT }\end{array}$ \\
\hline 31 & Quả & $\begin{array}{l}\text { xác định } \\
\text { tính trạng } \\
\text { quả có hại } \\
\text { (Tuberculati }\end{array}$ & $\begin{array}{c}\text { W. Zhang và } \\
\text { cộng sự (2010) }\end{array}$ & 5 & 7.9 & SSR04323 & (TTA)12 & 197 & $\begin{array}{c}\text { TGGTGGA } \\
\text { AAAGAAA } \\
\text { AAGGGA }\end{array}$ & $\begin{array}{l}\text { GCTAG } \\
\text { GGCAC } \\
\text { AAGAA } \\
\text { CGAAG }\end{array}$ \\
\hline 32 & & & & 5 & 48.4 & SSR03943 & (TA) 16 & 130 & $\begin{array}{c}\text { TTTTTGGT } \\
\text { GAAAAGG } \\
\text { AACGTG }\end{array}$ & $\begin{array}{c}\text { CACAA } \\
\text { AGCAA } \\
\text { AATTG } \\
\text { AGGGA } \\
\text { A } \\
\end{array}$ \\
\hline 33 & & $\begin{array}{c}\text { đắng } \\
\text { (bitterfree } \\
\text { foliage) }\end{array}$ & & 5 & 7.9 & SSR 15818 & (AT) 24 & 219 & $\begin{array}{c}\text { GGACATG } \\
\text { TCAACTC } \\
\text { CCCTGT }\end{array}$ & $\begin{array}{l}\text { GCCTC } \\
\text { TAGCC } \\
\text { TGAAA } \\
\text { GACCA }\end{array}$ \\
\hline 34 & & $\begin{array}{l}\text { không có lá } \\
\text { (virescent } \\
\text { leaf) }\end{array}$ & & 5 & 7.9 & SSR06003 & (AT) 26 & 156 & $\begin{array}{c}\text { TGAGGGG } \\
\text { CAAAATT } \\
\text { GGTAAA }\end{array}$ & $\begin{array}{l}\text { TTGGG } \\
\text { TGTCA } \\
\text { AATGG } \\
\text { AAGAA }\end{array}$ \\
\hline 35 & & & sự (2011) & 6 & 33.3 & SSR 18405 & (TAT)13 & 210 & $\begin{array}{c}\text { CGCAGGT } \\
\text { GCATCTC } \\
\text { ATGTAA }\end{array}$ & $\begin{array}{l}\text { GACAA } \\
\text { ACAAG } \\
\text { GGGAC } \\
\text { GAAAA } \\
\end{array}$ \\
\hline 36 & & $\begin{array}{l}\text { (virescent } \\
\text { leaf) }\end{array}$ & & 6 & 10.8 & SSR00004 & (AT) 15 & 216 & $\begin{array}{c}\text { TTCATTG } \\
\text { CAAAGCA } \\
\text { CACACA }\end{array}$ & $\begin{array}{c}\text { TGAAA } \\
\text { AGAGG } \\
\text { GAACA } \\
\text { AAAGC } \\
\text { A } \\
\end{array}$ \\
\hline 37 & \multirow{4}{*}{ Quả } & \multirow{4}{*}{$\begin{array}{l}\text { Chiều dài và } \\
\text { đường kính }\end{array}$} & \multirow{4}{*}{$\begin{array}{c}\text { T. Zhang và } \\
\text { cộng sự (2019) }\end{array}$} & 1 & 64.5 & SSR20354 & (AT) 31 & 177 & $\begin{array}{c}\text { AGATGCC } \\
\text { CCATTCA } \\
\text { GTTTTG }\end{array}$ & $\begin{array}{l}\text { TTGAA } \\
\text { GGAGA } \\
\text { GAGGG } \\
\text { AATGG }\end{array}$ \\
\hline 38 & & & & 1 & 84.1 & SSR17922 & $\begin{array}{c}\text { (AAT)7(A } \\
\text { AG) } 11\end{array}$ & 197 & $\begin{array}{c}\text { CATTCTA } \\
\text { GGTCAAT } \\
\text { GAATCGC } \\
\text { A }\end{array}$ & $\begin{array}{l}\text { GCAAA } \\
\text { GTTGC } \\
\text { CACAT } \\
\text { TGAAG }\end{array}$ \\
\hline 39 & & & & 2 & 37.5 & SSR22558 & (TA) 23 & 170 & $\begin{array}{c}\text { TCAACTT } \\
\text { ATCCCTC } \\
\text { TTTCTATT } \\
\text { TTCC }\end{array}$ & $\begin{array}{c}\text { GGCAA } \\
\text { TCATT } \\
\text { ACCAA } \\
\text { AAACC } \\
\text { A }\end{array}$ \\
\hline 40 & & & & 2 & 59.3 & SSR 10518 & $\begin{array}{l}\text { (ATTA)5( } \\
\text { A) } 30\end{array}$ & 211 & $\begin{array}{l}\text { TCTAATT } \\
\text { CGCTCCG }\end{array}$ & $\begin{array}{l}\text { TTGCA } \\
\text { GCGAA }\end{array}$ \\
\hline
\end{tabular}




\begin{tabular}{|c|c|c|c|c|c|c|c|c|c|c|}
\hline SSR & Bệnh & Kháng & TLTK & Chr. & $\mathbf{c M}$ & Loci & Motif & $\underset{\text { size }}{\text { Fragment }}$ & $\begin{array}{c}\text { Forward } \\
\text { primer }\end{array}$ & $\begin{array}{c}\text { Reverse } \\
\text { primer }\end{array}$ \\
\hline & & & & & & & & & GATGAT & $\begin{array}{l}\text { CAATC } \\
\text { CTGTA } \\
\end{array}$ \\
\hline 41 & & & & 3 & 9.5 & SSR22158 & (TA) 30 & 187 & $\begin{array}{c}\text { TTGAAAC } \\
\text { TTGTGGC } \\
\text { TACCCC }\end{array}$ & $\begin{array}{l}\text { ATCAA } \\
\text { CTCTG } \\
\text { AGACA } \\
\text { TAATG } \\
\text { GATTT }\end{array}$ \\
\hline 42 & & & & 3 & 31.7 & SSR03918 & $\begin{array}{c}\text { (CTTTGC) } \\
7\end{array}$ & 143 & $\begin{array}{l}\text { TGAGGGT } \\
\text { GAGACAA } \\
\text { CAAATCA }\end{array}$ & $\begin{array}{c}\text { TGTGT } \\
\text { TTGAC } \\
\text { AAAGG } \\
\text { AAAGG } \\
\text { AA } \\
\end{array}$ \\
\hline 43 & & & & 1 & 54.8 & SSR04805 & $(\mathrm{GAC}) 9$ & 139 & $\begin{array}{c}\text { TCATGTC } \\
\text { AAGCGAA } \\
\text { GGAAGA }\end{array}$ & $\begin{array}{l}\text { TACTG } \\
\text { TCCGA } \\
\text { ACGTG } \\
\text { TTCCA } \\
\end{array}$ \\
\hline 44 & & & & 1 & 84.1 & SSR23049 & (TGGGT)6 & 168 & $\begin{array}{c}\text { GCTTGCT } \\
\text { GCTAAAG } \\
\text { GGGATT }\end{array}$ & $\begin{array}{l}\text { TTCGT } \\
\text { CAAAT } \\
\text { TTGGT } \\
\text { TGTCG } \\
\end{array}$ \\
\hline 45 & & & & 1 & 66.6 & SSR03860 & (AT) 17 & 187 & $\begin{array}{l}\text { GCCCTTA } \\
\text { TTAACCC } \\
\text { AAGTTGC }\end{array}$ & $\begin{array}{l}\text { AATTG } \\
\text { AGGGG } \\
\text { CACTT } \\
\text { ATTGG } \\
\end{array}$ \\
\hline 46 & & & & 1 & 78.2 & SSR05723 & (AT) 17 & 209 & $\begin{array}{c}\text { TGGCTTTT } \\
\text { CTGTCAC } \\
\text { GTCC }\end{array}$ & $\begin{array}{c}\text { TCCAT } \\
\text { GGTAC } \\
\text { AACAA } \\
\text { GAATC } \\
\text { ACA }\end{array}$ \\
\hline 47 & \multirow{4}{*}{$\begin{array}{c}\text { Đa } \\
\text { dạng } \\
\text { di } \\
\text { truyền }\end{array}$} & & \multirow{4}{*}{$\begin{array}{l}\text { Pandey, Ansari, } \\
\text { Mishra, } \\
\text { Singh, } \\
\text { và Singh } \\
\text { (2013) }\end{array}$} & 3 & 5.3 & SSR05737 & (CT) 17 & 185 & $\begin{array}{c}\text { TTGCCTTC } \\
\text { GTAAGCA } \\
\text { AAAA }\end{array}$ & $\begin{array}{l}\text { GAAGT } \\
\text { AAATG } \\
\text { GGTTG } \\
\text { GACGC } \\
\end{array}$ \\
\hline 48 & & & & 2 & 66.3 & SSR 12810 & (ATT)13 & 177 & $\begin{array}{r}\text { TTCCCAC } \\
\text { AAAACAA } \\
\text { ATCTTGG }\end{array}$ & $\begin{array}{c}\text { TTTTG } \\
\text { GAGAG } \\
\text { AAAAG } \\
\text { GTTGG } \\
\text { A } \\
\end{array}$ \\
\hline 49 & & & & 7 & 0 & SSR15477 & (AAAG) 12 & 213 & $\begin{array}{c}\text { CTGCCAT } \\
\text { TTCTGGG } \\
\text { TTTGAT }\end{array}$ & $\begin{array}{l}\text { AATTC } \\
\text { TTCTG } \\
\text { GGAAT } \\
\text { GGCCT } \\
\end{array}$ \\
\hline 50 & & & & 3 & 2.2 & SSR00670 & (GAA)8 & 156 & $\begin{array}{c}\text { TCTCAAA } \\
\text { CCAAGAA } \\
\text { TTGGGG }\end{array}$ & $\begin{array}{c}\text { TCCAT } \\
\text { GGAAG } \\
\text { CAGAT } \\
\text { CTTAA } \\
\text { AAA } \\
\end{array}$ \\
\hline 51 & & & \multirow{2}{*}{$\begin{array}{l}\text { Weng và cộng } \\
\text { sự (2015) }\end{array}$} & 1 & 22.7 & SSR21336 & (AGAA)5 & 190 & $\begin{array}{c}\text { CTGCTGC } \\
\text { TAGAAAG } \\
\text { GCTGCT }\end{array}$ & $\begin{array}{c}\text { CATCA } \\
\text { GCTGA } \\
\text { ATTAC } \\
\text { GAGGC } \\
T \\
\end{array}$ \\
\hline 52 & & & & 6 & 37.6 & SSR03932 & (ATT) 3 & 158 & $\begin{array}{c}\text { CTTTTTGG } \\
\text { GGACCCT } \\
\text { TCATT }\end{array}$ & $\begin{array}{l}\text { CACGA } \\
\text { ATGCT } \\
\text { GCTCT } \\
\text { AACCA }\end{array}$ \\
\hline
\end{tabular}

Nguồn: Kết quả xử lý dữ liệu của nhóm tác giả

Chúng tôi thu nhận 52 mồi SSR. Các mồi này nằm trải dài trên 07 NST của dưa leo. 
Ngoài ra, những mồi này đã được chứng minh liên kết với những tính trạng quan trọng trong chọn giống dưa leo bao gồm đường kính và kích thước lá (06 SSR), hình dạng quả, chiều dài quả (10 SSR), hoa (02 SSR), khả năng kháng bệnh (21 SSR) và có khả năng được sử dụng để phân tích đa dạng di truyền (06 SSR ).

\subsubsection{Xác định nhiệt độ bắt cặp phù hợp của các mồi SSR cho phản ứng PCR}

Tiến hành xác định nhiệt độ bắt cặp tối ưu cho 50 cặp mồi SSR đã xác định ở trên. Tiến hành chỉnh nồng độ về $10 \mathrm{ng} / \mu \mathrm{l}$ cho mỗi mồi SSR. Thực hiện phản ứng PCR với DNA mẫu đã được kiểm tra kiểu gene trước đó là đồng hợp qui định cho cây có toàn hoa cái làm DNA mạch khuôn với chu trình nhiệt và thành phần phản ứng đã mô tả ở trên. Kết quả điện di của tất cả các mồi được thể hiện trong Hình 1 bên dưới.
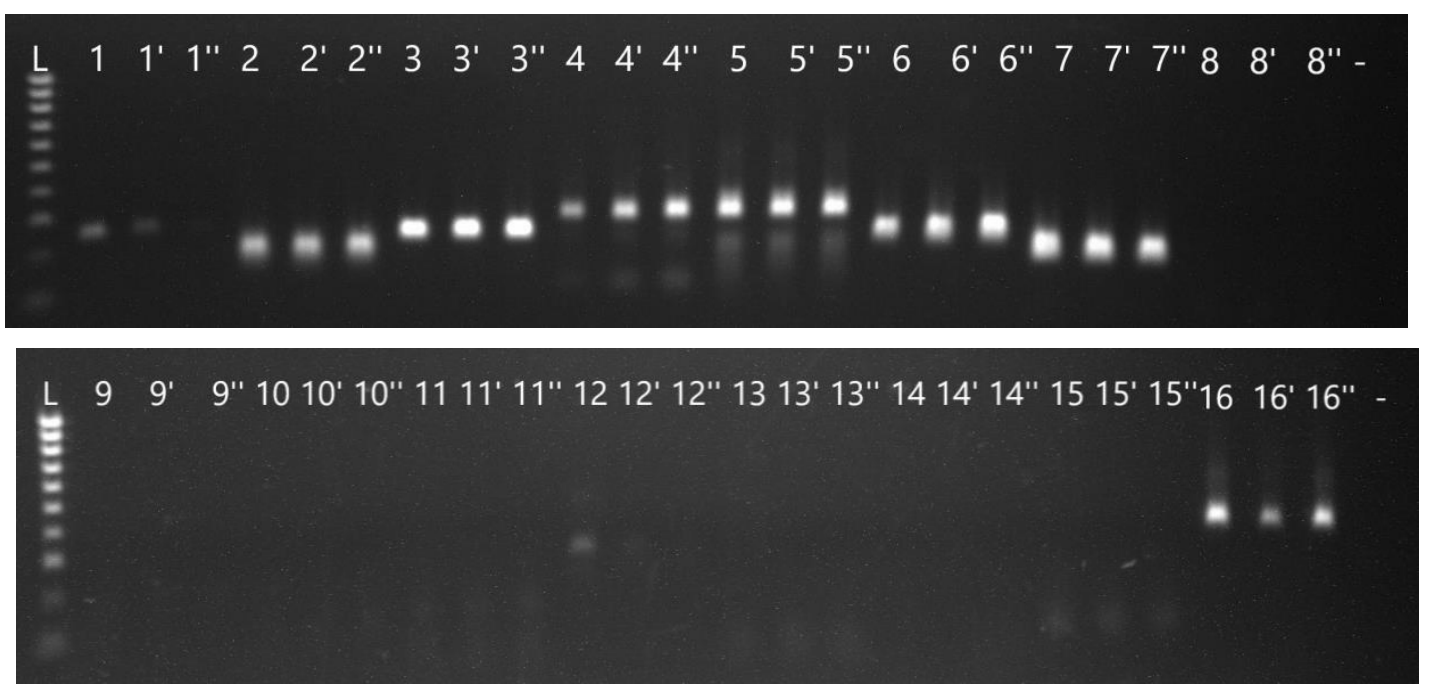

L $1717^{\prime} 17^{\prime \prime} 181^{\prime} 18^{\prime \prime} 191^{\prime \prime} 19^{\prime \prime} 2020^{\prime} 20^{\prime \prime} 2121^{\prime} 21^{\prime \prime} 2222^{\prime} 22^{\prime \prime} 2323^{\prime} 23^{\prime \prime} 2424^{\prime} 24^{\prime \prime}$

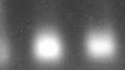

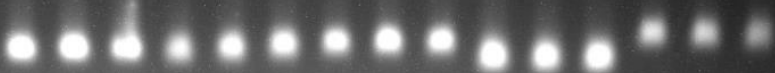

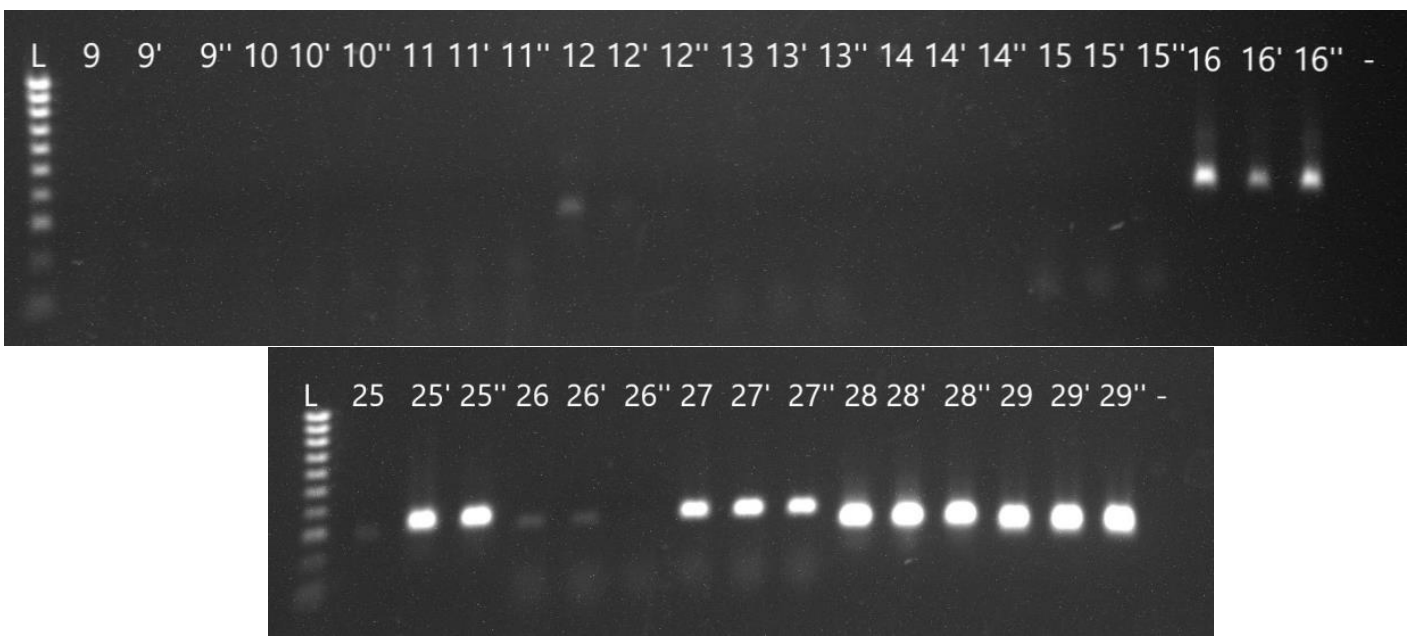




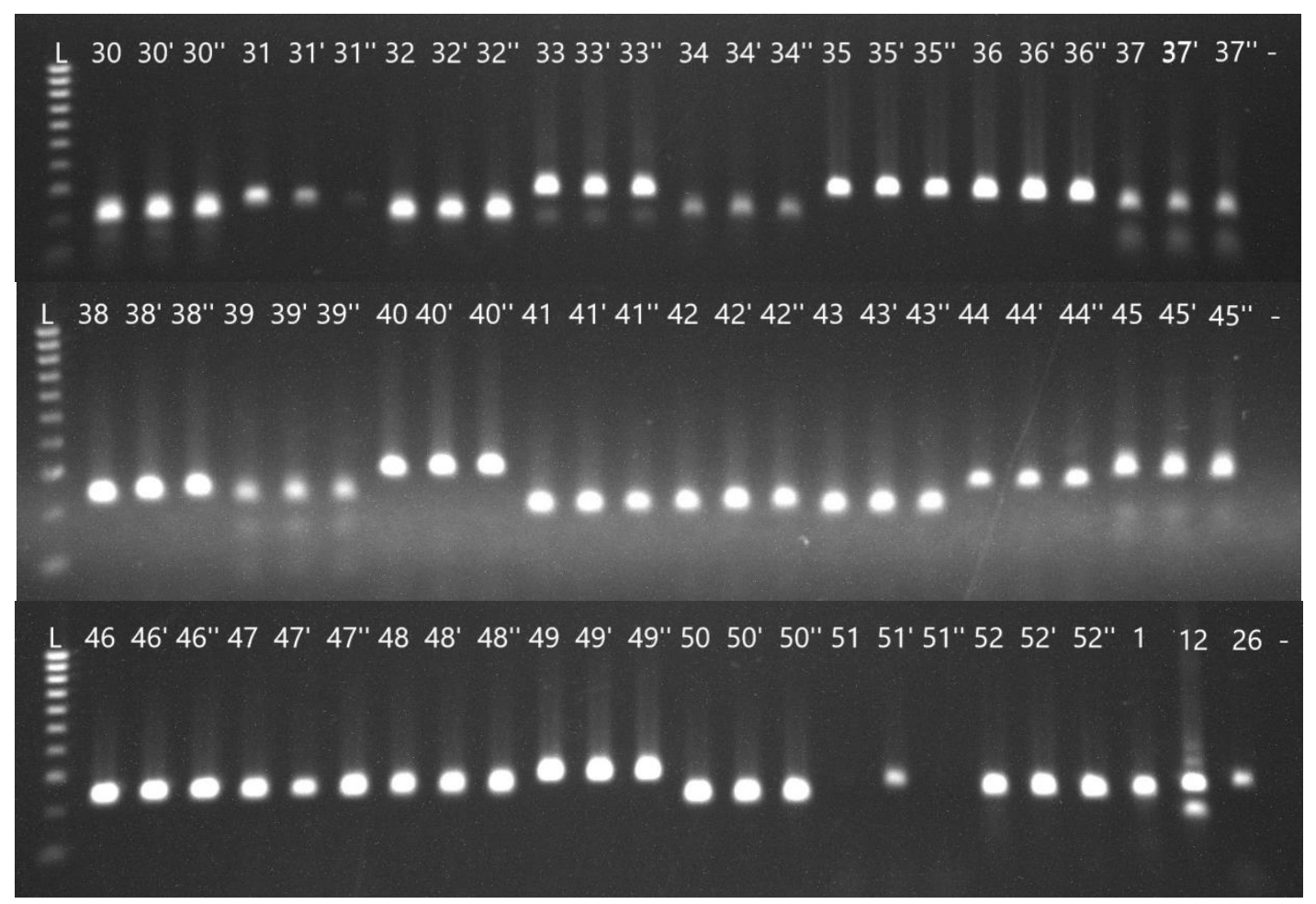

Hình 1. PCR với gradient nhiệt độ để xác định nhiệt độ bắt cặp cho tất cả 50 mồi SSR. Các dấu 'và' tương ứng với nhiệt độ bắt cặp số 02 và 03 trong Bảng 1 cho mỗi mồi

Kết quả cho thấy hầu hết các mồi đều cho kết quả rõ ở gradient nhiệt độ khảo sát. Tuy nhiên, có 08 mồi SSR không chạy ra kết quả là $08,09,10,11,13,14,15,18$ và 03 mồi cho ra kết quả mờ là $01,12,26$. Đối với 03 mồi cho ra kết quả mờ này, tiến hành giảm nhiệt độ bắt cặp 10 độ so với nhiệt độ bắt cặp gradient chọn ban đầu ở Bảng 1 . Kết quả cho thấy khi giảm nhiệt độ bắt cặp, các mồi này đều cho kết quả tốt (Hình 1).

Đối với 08 mồi SSR chưa xác định được nhiệt độ bắt cặp, tiến hành chạy gradiant nhiệt độ bắt cặp lại cho 08 mồi SSR này với mẫu DNA từ cây có kiểu gene đồng hợp quy định tính trạng toàn hoa đực đã xác định trước đó. Tuy nhiên, chúng tôi không thu được vạch sản phẩm mong đợi. Kết quả thể hiện ở Hình 2.

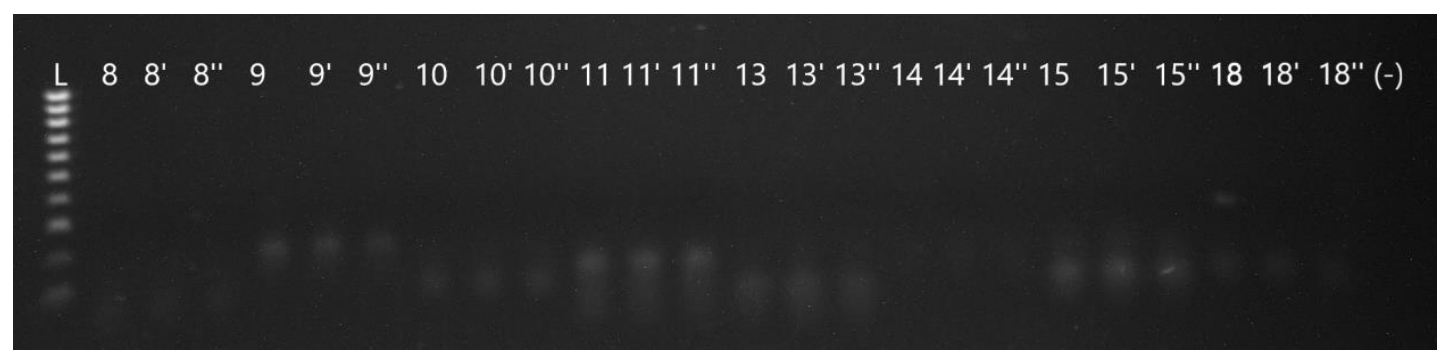

Hình 2. PCR với gradient nhiệt độ bắt cặp cho 08 mồi SSR với DNA từ cây có kiểu gene đồng hợp quy định toàn hoa đực

Tiếp theo, tiến hành chạy gradiant nhiệt độ bắt cặp lại cho 08 mồi SSR với mẫu B15 (gyno) với nhiệt độ giảm lần lượt 10 và 05 độ so với nhiệt độ bắt cặp đã xác định trước đó. Kết quả thể hiện trong Hình 3 và 4 . 


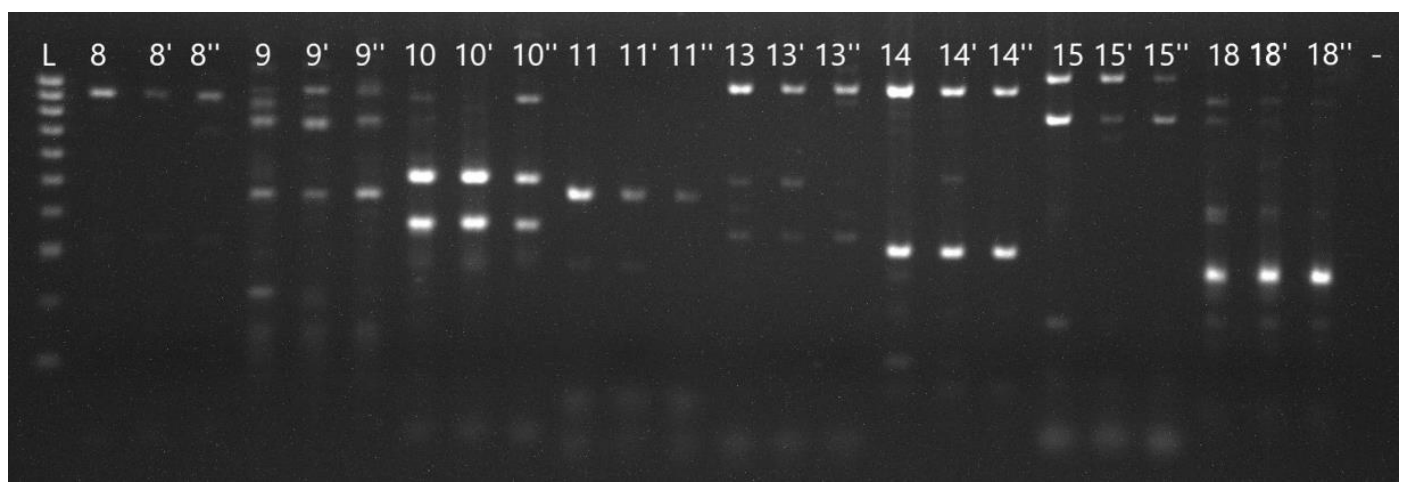

Hình 3. PCR với với gradient giảm 10 độ so với nhiệt độ gradient xác định ban đầu cho 8 mồi SSR khó khuyếch đại

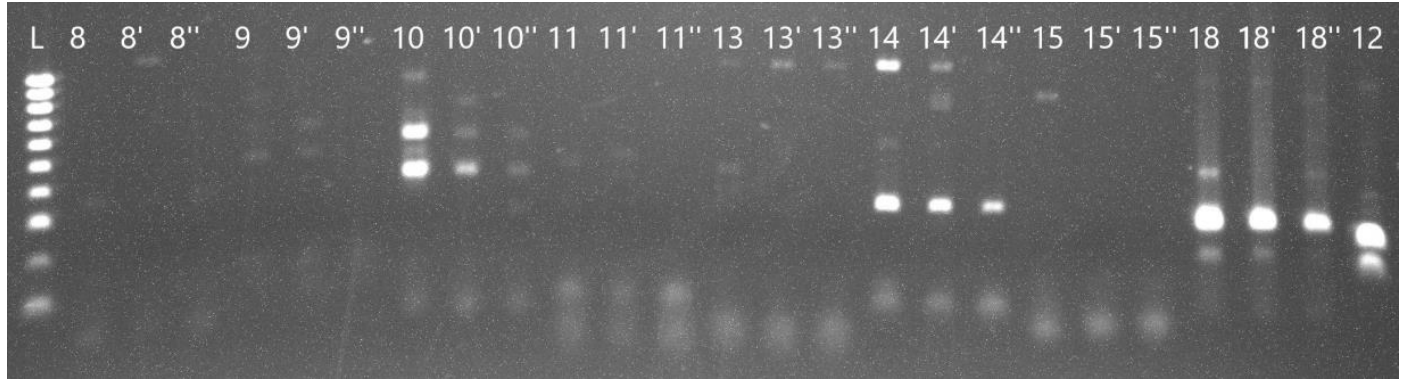

Hình 4. PCR với với gradient giảm 05 độ so với nhiệt độ gradient xác định ban đầu cho 08 mồi SSR khó khuyếch đại

Kết quả cho thấy khi giảm nhiệt độ bắt cặp xuống 10 và 05 độ, mồi 14,18 ra được nhiệt độ phù hợp, mồi 09 bị mờ và vạch tạp, mồi 10 sáng nhưng bị vạch tạp. Các mồi không có vạch lần lượt là $08,11,13,15$.

Như vậy, chúng tôi đã tìm ra được nhiệt độ bắt cặp thích hợp cho 46 cặp mồi SSR (còn 06 cặp mồi chưa tìm được nhiệt độ thích hợp). Kết quả được tóm tắt trong Bảng 3.

\section{Bảng 3}

Nhiệt độ bắt cặp cho phản ứng PCR của 46 mồi SSR sử dụng

\begin{tabular}{|c|c|c|c|}
\hline $\begin{array}{c}\text { Số thứ tự mồi } \\
\text { SSR }\end{array}$ & $\begin{array}{c}\text { Nhiệt độ bắt cặp phù } \\
\text { họ̣p }\end{array}$ & Số thứ tụ̂ mồi SSR & $\begin{array}{c}\text { Nhiệt độ bắt cặp phù } \\
\text { họ̣p }\end{array}$ \\
\hline SSR1 & $50^{\circ}$ & SSR26 & $44^{\circ}$ \\
\hline SSR2 & $59^{\circ}$ & SSR27 & $59^{\circ}$ \\
\hline SSR3 & $58^{\circ}$ & SSR28 & $66^{\circ}$ \\
\hline SSR4 & $58^{\circ}$ & SSR29 & $59^{\circ}$ \\
\hline SSR5 & $61^{\circ}$ & SSR30 & $57^{\circ}$ \\
\hline SSR6 & $58^{\circ}$ & SSR31 & $57^{\circ}$ \\
\hline SSR7 & $61^{\circ}$ & SSR32 & $58^{\circ}$ \\
\hline SSR8 & & SSR33 & $63^{\circ}$ \\
\hline
\end{tabular}




\begin{tabular}{|c|c|c|c|}
\hline $\begin{array}{c}\text { Số thứ tự mồi } \\
\text { SSR }\end{array}$ & $\begin{array}{c}\text { Nhiệt độ bắt cặp phù } \\
\text { họ̣p }\end{array}$ & Số thứ tự mồi SSR & $\begin{array}{c}\text { Nhiệt độ bắt cặp phù } \\
\text { họ̣p }\end{array}$ \\
\hline SSR9 & & SSR34 & $54^{\circ}$ \\
\hline SSR10 & & SSR35 & $59^{\circ}$ \\
\hline SSR11 & & SSR36 & $57^{\circ}$ \\
\hline SSR12 & $55^{\circ}$ & SSR37 & $59^{\circ}$ \\
\hline SSR13 & & SSR38 & $59^{\circ}$ \\
\hline SSR14 & $58^{\circ}$ & SSR39 & $62^{\circ}$ \\
\hline SSR15 & & SSR40 & $58^{\circ}$ \\
\hline SSR16 & $63^{\circ}$ & SSR41 & $61^{\circ}$ \\
\hline SSR17 & $61^{\circ}$ & SSR42 & $59^{\circ}$ \\
\hline SSR18 & $53^{\circ}$ & SSR43 & $59^{\circ}$ \\
\hline SSR19 & $60^{\circ}$ & SSR44 & $58^{\circ}$ \\
\hline SSR20 & $59^{\circ}$ & SSR45 & $62^{\circ}$ \\
\hline SSR21 & $62^{\circ}$ & SSR46 & $60^{\circ}$ \\
\hline SSR22 & $61^{\circ}$ & SSR47 & $58^{\circ}$ \\
\hline SSR23 & $62^{\circ}$ & SSR48 & $58^{\circ}$ \\
\hline SSR24 & $59^{\circ}$ & SSR49 & $58^{\circ}$ \\
\hline SSR25 & $62^{\circ}$ & SSR50 & $59^{\circ}$ \\
\hline SSR26 & $44^{\circ}$ & SSR51 & $60^{\circ}$ \\
\hline SSR27 & $59^{\circ}$ & SSR52 & $60^{\circ}$ \\
\hline
\end{tabular}

Nguồn: Kết quả xử lý dữ liệu của nhóm tác giả

\subsection{Thảo luận}

Năng suất và chất lượng là hai yếu tố chính của tiến trình cải thiện giống dưa leo, hai đặc tính này cùng với những tính trạng có liên quan là những đặc điểm được quan tâm nhiều nhất của các nhà chọn giống. Việc chọn ra giống dưa leo tốt bằng chỉ thị phân từ giúp các nhà chọn giống rút ngắn thời gian, tiết kiệm chi phí. Hiện nay, việc chọn lọc dưa leo tốt nhờ hỗ trợ phân tử hay cụ thể hơn là chuyển một số đặc điểm ưu thế lai quan trọng từ dòng dưa leo này sang dòng dưa leo khác là hoàn toàn khả thi: Bộ gene của dưa leo đã được giải trình tự; Bản đồ liên kết có độ bao phủ của các marker đã được xác định; Vị trí các tính trạng nông học quan trọng nhưng phức tạp ở dưa leo đã được xác định trên bộ gene và các marker có sự liên kết với các tính trạng này đã được xác định. Phương pháp lai ngược với sự hỗ trợ của chỉ thị phân tử đã được chứng minh có hiệu quả cao hơn so với phương pháp truyền thống trong việc chuyển gene từ dòng này sang dòng khác trong cùng một loài. Phương pháp này đã được áp dụng trong một số cây trồng ở Việt Nam và đã cho thấy kết quả tốt. Để có thể áp dụng chỉ thị phân tử hỗ trợ chọn giống, cần thiết 
phải xây dựng một cơ sở dữ liệu SSR để làm cơ sở cho bước sàng lọc phía sau.

Trong nghiên cứu này chúng tôi đã bước đầu xây dựng bộ cơ sở dữ liệu gồm 52 SSR có liên kết với những tính trạng quan trọng cho chọn giống của dưa leo như đường kính và kích thước lá, hình dạng quả, chiều dài quả, hoa, khả năng kháng bệnh và trải dài trên 07 nhóm liên kết của dưa leo. Ngoài ra, nhiệt độ bắt cặp của các mồi SSR này cho phản ứng PCR khuếch đại DNA dưa leo đã được bước đầu xác định. Mặc dù một số mồi SSR cho thấy khó khuếch đại, các mồi SSR còn lại ở nhiệt độ bắt cặp tối ưu cho sản phẩm khá đặc hiệu, sản phẩm mạnh. Đây là một trong cơ sở dữ liệu quan trọng trước khi chúng tôi thực hiện xây dựng bản đồ liên kết của các SSR với các giống dưa leo để chọn giống tiếp theo.

\section{Kết luận và gợi ý}

Chúng tôi đã xác định được 52 SSR có liên kết với các tính trạng quan trọng trong chọn giống dưa leo như đường kính và kích thước lá, hình dạng quả, chiều dài quả, hoa, khả năng kháng bệnh. Nhiệt độ bắt cặp tối ưu cho phản ứng PCR tương ứng với từng mồi SSR đã được xác định.

\section{LỜI CÁM ƠN}

Nghiên cứu này được tài trợ bởi Sở Khoa học Công nghệ Thành phố Hồ Chí Minh cho TS. Lê Thị Kính và các cộng sự năm 2020 (QĐ-240/SKHCN).

\section{Tài liệu tham khảo}

Call, A. D., Criswell, A. D., Wehner, T. C., Klosinska, U., \& Kozik, E. U. (2012). Screening cucumber for resistance to downy mildew caused by Pseudoperonospora cubensis (Berk. and Curt.) Rostov. Crop Science, 52(2), 577-592.

Fazio, G., Staub, J., \& Stevens, M. (2003). Genetic mapping and QTL analysis of horticultural traits in cucumber (Cucumis sativus L.) using recombinant inbred lines. Theoretical and Applied Genetics, 107(5), 864-874.

Huang, S., Li, R., Zhang, Z., Li, L., Gu, X., Fan, W., . . Li, S. (2009). The genome of the cucumber, Cucumis sativus L. Nature Genetics, 41(12), 1275-1281.

Jat, G. S., Munshi, A. D., Behera, T. K., Choudhary, H., Dash, P., Ravindran, A., \& Kumari, S. (2019). Genetics and molecular mapping of gynoecious (F) locus in cucumber (Cucumis sativus L.). The Journal of Horticultural Science and Biotechnology, 94(1), 24-32.

Miao, H., Zhang, S., Wang, X., Zhang, Z., Li, M., Mu, S., . . Gu, X. (2011). A linkage map of cultivated cucumber (Cucumis sativus L.) with 248 microsatellite marker loci and seven genes for horticulturally important traits. Euphytica, 182(2), 167-176.

Naegele, R. P., Quesada-Ocampo, L. M., Kurjan, J. D., Saude, C., \& Hausbeck, M. K. (2016). Regional and temporal population structure of pseudoperonospora cubensis in Michigan and Ontario. Phytopathology, 106(4), 372-379.

Nie, J., He, H., Peng, J., Yang, X., Bie, B., Zhao, J., . . Cai, R. (2015). Identification and fine mapping of pm5.1: A recessive gene for powdery mildew resistance in cucumber (Cucumis sativus L.). Molecular Breeding, 35(1), 1-13.

Pandey, S., Ansari, W. A., Mishra, V. K., Singh, A. K., \& Singh, M. (2013). Genetic diversity 
in Indian cucumber based on microsatellite and morphological markers. Biochemical Systematics and Ecology, 51, 19-27.

Ponting, C. P., Schultz, J., Milpetz, F., \& Bork, P. (1999). SMART: Identification and annotation of domains from signalling and extracellular protein sequences. Nucleic Acids Research, 27(1), 229-232.

Rahman, A., Anisuzzaman, M., Ahmed, F., Islam, A., \& Naderuzzaman, A. (2008). Study of nutritive value and medicinal uses of cultivated cucurbits. Journal of Applied Sciences Research, 4(5), 555-558.

Ren, Y., Zhang, Z., Liu, J., Staub, J. E., Han, Y., Cheng, Z., . . . Huang, S. (2009). An integrated genetic and cytogenetic map of the cucumber genome. PLoS One, 4(6), Article e5795. doi:10.1371/journal.pone.0005795

Ribaut, J. M., \& Betrán, J. (1999). Single large-scale marker-assisted selection (sls-mas). Molecular Breeding, 5(6), 531-541.

Shi, L., Yang, Y., Xie, Q., Miao, H., Bo, K., Song, Z., . . G Gu, X. (2018). Inheritance and QTL mapping of cucumber mosaic virus resistance in cucumber (Cucumis Sativus L.). PloS One, 13(7), Article e0200571.

Szczechura, W., Staniaszek, M., Klosinska, U., \& Kozik, E. U. (2015). Molecular analysis of new sources of resistance to Pseudoperonospora cubensis (Berk. et Curt.) Rostovzev in cucumber. Russian Journal of Genetics, 51(10), 974-979.

Weng, Y., Colle, M., Wang, Y., Yang, L., Rubinstein, M., Sherman, A., . . . Grumet, R. (2015). Qtl mapping in multiple populations and development stages reveals dynamic quantitative trait loci for fruit size in cucumbers of different market classes. Theoretical and Applied Genetics, 128(9), 1747-1763.

Weng, Y., Johnson, S., Staub, J. E., \& Huang, S. (2010). An extended intervarietal microsatellite linkage map of cucumber, Cucumis sativus L. HortScience, 45(6), 882886.

Zhang, S., Liu, M., Miao, H., Zhang, S., Yang, Y., Xie, B., . . . Gu, X. (2013). Chromosomal mapping and QTL analysis of resistance to downy mildew in cucumis sativus. Plant Disease, 97(2), 245-251.

Zhang, T., Li, X., Yang, Y., Guo, X., Feng, Q., Dong, X., \& Chen, S. (2019). Genetic analysis and QTL mapping of fruit length and diameter in a cucumber (cucumber sativus L.) Recombinant Inbred Line (RIL) population. Scientia Horticulturae, 250, 214-222.

Zhang, W., He, H., Guan, Y., Du, H., Yuan, L., Li, Z., . . . Cai, R. (2010). Identification and mapping of molecular markers linked to the tuberculate fruit gene in the cucumber (Cucumis sativus L.). Theoretical and Applied Genetics, 120(3), 645-654.

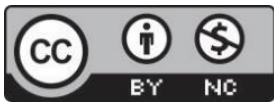

Creative Commons Attribution-NonCommercial 4.0 International License. 